5. Coretti MC, Anderson TJ, Benjamin EJ, Celermayer DS, Charbonneau F, Creager MA, Deanfield J, Drexler H, Gerhard-Herman M, Herrington D, et al. Guidelines for the ultrasound assessment of endothelial-dependent flow-mediated vasodilatation of the brachial artery: a report of the International Brachial Artery Reactivity Task Force. J Am Coll Cardiol 2002;39:257-265.

6. Virdis A, Ghiadoni L, Lucarini R, Di Legge V, Taddei S, Salvetti A. Presence of cardiovascular structural changes in essential hypertensive patients with coronary microvascular disease and effects of long-term treatment. Am J Hypertens 1996;9:361-369.

7. Bellamy MF, Goodfellow J, Tweddel AC, Dunstan FDJ, Lewis MJ, Henderson AH. Syndrome X and endothelial dysfunction. Cardiovasc Res 1998;40:410-417.
8. Vrints CJ, Bult H, Hitter E, Herman AG, Snoeck JP. Impaired endothelium dependent coronary vasodilatation in patients with angina pectoris and normal coronary arteriograms. J Am Coll Cardiol 1992;19:21-31.

9. Motz W, Vogt M, Rabenau O, Scheler S, Luckhoff A, Strauer BE. Evidence of endothelial dysfunction in coronary resistance vessels in patients with angina pectoris and normal coronary arteriograms. Am J Cardiol 1991;68:996-1003. 10. Zhang X, Zhao SP, Li XP, Gao M, Zhou QC. Endothelium-dependent and -independent functions are impaired in patients with coronary heart disease. Atherosclerosis 2000;149:19-24.

11. Botker HE, Sonne HS, Sorensen KE. Frequency of systemic microvascular dysfunction in syndrome X and in variant angina. Am J Cardiol 1996;78:182-186.

\title{
Prevalence and Determinants of Breast Arterial Calcium in Women at High Risk of Cardiovascular Disease
}

\author{
Angela H. E. M. Maas, MD, Yvonne T. van der Schouw, PhD, \\ Willem P. Th. M. Mali, MD, PhD, and Yolanda van der Graaf, MD, PhD
}

\begin{abstract}
Calcium deposits in breast arteries are commonly seen on mammograms, and their frequency increases with age, especially after menopause. The investigators studied the prevalence of breast arterial calcium in $\mathbf{6 0 0}$ women at high risk for cardiovascular events and assessed whether classic cardiovascular risk factors are independent determinants of these calcifications. (C) 2004 by Excerpta Medica, Inc.
\end{abstract}

(Am J Cardiol 2004;94:655-659)

- reast cancer screening programs may offer a new - way to identify women at high risk for cardiovascular events; these program have the advantage of already running in many Western countries. Accumulating evidence suggests that the presence of breast arterial calcium (BAC) on mammograms may serve as a marker for generalized vascular disease..$^{1,2}$ In a large, cross-sectional study involving 12,239 women aged 50 to 69 years who participated in a breast cancer screening program, we found a prevalence of BAC of $9 \%$, with a significantly greater prevalence of $15.4 \%$ in diabetic subjects. ${ }^{2-5}$ At follow-up, overall mortality was significantly greater in women with BAC (odds ratio [OR] $1.29,95 \%$ confidence interval [CI] 1.06 to 1.58) than in women without BAC, with an excess mortality in diabetic women of $74 \%$ (OR 1.74, 95\% CI 1.19 to 2.56). However, to date, it has not been established to what extent the various determinants of cardiovascular risk contribute to the presence of these calcifications. We analyzed the mammograms of 600

From the Department of Cardiology, Isala Klinieken, Zwolle and the Julius Center for Health Sciences and Primary Care and the Department of Radiology, University Medical Center Utrecht, Utrecht, The Netherlands. This study was financially supported by research grant 2100.086 of ZonMw (The Netherlands Organization for Health Research and Development), The Hague, The Netherlands. Dr. Maas's address is: Isala Klinieken, Department of Cardiology, Dr. van Heesweg 2, 8025 AB Zwolle, The Netherlands. E-mail: a.maas@diagram-zwolle.nl. Manuscript received February 20, 2004; revised manuscript received and accepted May 6, 2004

\begin{tabular}{|c|c|}
\hline Criterion & Points \\
\hline $\begin{array}{l}\text { Myocardial infarction (MI) 3-36 mo before } \\
\text { randomization }\end{array}$ & 4 \\
\hline $\begin{array}{l}\text { Angina pectoris with documented coronary disease } \\
\text { on angiogram }\end{array}$ & 4 \\
\hline $\begin{array}{l}\text { Coronary angioplasty 6-36 mo before } \\
\text { randomization }\end{array}$ & 4 \\
\hline Coronary bypass 3-36 mo before randomization & 4 \\
\hline $\begin{array}{l}\text { Lower extremity arterial disease, documented by } \\
\text { symptoms, or ankle/brachial index }<0.9 \text {, } \\
\text { revascularization or nontraumatic amputation }\end{array}$ & 4 \\
\hline $\begin{array}{l}\text { Current smoker and hypertension and } \\
\text { hyperlipidemia }\end{array}$ & 4 \\
\hline $\begin{array}{l}\text { Diabetes mellitus (fasting glucose }>140 \mathrm{mg} / \mathrm{dl} \text { or } \\
\text { on medication) }\end{array}$ & 3 \\
\hline $\mathrm{MI}>36$ mo before randomization & 2 \\
\hline $\begin{array}{l}\text { Coronary angioplasty }>36 \text { mo before } \\
\text { randomization }\end{array}$ & 2 \\
\hline Coronary bypass $>36$ mo before randomization & 2 \\
\hline Age $\geq 70$ yrs & 2 \\
\hline Age $>65$ yrs and $<70$ yrs & 1 \\
\hline $\begin{array}{l}\text { Current smoker by self-report ( } \geq 10 \text { cigarettes for } 6 \\
\text { mo before enrollment) }\end{array}$ & 1 \\
\hline $\begin{array}{l}\text { Systolic blood pressure }>160 \mathrm{~mm} \mathrm{Hg} \text { or diastolic } \\
\text { blood pressure }>95 \mathrm{~mm} \mathrm{Hg} \text { or on medication }\end{array}$ & 1 \\
\hline $\begin{array}{l}\text { Low-density lipoprotein cholesterol }>160 \mathrm{mg} / \mathrm{dl} \text { or } \\
\text { high-density lipoprotein cholesterol }>45 \mathrm{mg} / \mathrm{dl} \\
\text { with triglycerides }>250 \mathrm{mg} / \mathrm{dl} \text { or on } \\
\text { medication) }\end{array}$ & 1 \\
\hline
\end{tabular}

participants included in the high-risk cohort of the Raloxifene Use for the Heart (RUTH) study.

$$
\bullet \cdot
$$

The 610 participants of the Dutch subset of patients from the RUTH study were included in this crosssectional study. The RUTH trial began 1998 and is a multicenter, randomized, double-blind, placebo-controlled clinical trial involving women from 26 countries. Its aim is to evaluate treatment with raloxifene $60 \mathrm{mg}$ versus placebo in 10,101 postmenopausal 


$$
\frac{1}{6}
$$


TABLE 2 Prevalence of Risk Factors in Women With and Without BAC $(n=600)$

\begin{tabular}{|c|c|c|}
\hline \multirow[b]{2}{*}{ Risk Factor } & \multicolumn{2}{|c|}{ BAC } \\
\hline & $+23 \%(n=138)$ & $077 \%(n=462)$ \\
\hline Age (yrs) & $70.4 \pm 6$ & $66.5 \pm 6$ \\
\hline Age $\geq 70$ yrs & $35.4 \%$ & $15.5 \%$ \\
\hline Age at menopause (yrs) & 47.9 & 48.0 \\
\hline \multicolumn{3}{|l|}{ Parity } \\
\hline 0-1 child & $8(14 \%)$ & $50(86 \%)$ \\
\hline 2-3 children & $60(19 \%)$ & $260(81 \%)$ \\
\hline 4-5 children & $46(35 \%)$ & 87 (65\%) \\
\hline$\geq 6$ children & $22(51 \%)$ & $21(49 \%)$ \\
\hline Body mass index $\left(\mathrm{kg} / \mathrm{m}^{2}\right)$ & $28 \pm 4$ & $28 \pm 4$ \\
\hline Systolic blood pressure $(\mathrm{mm} \mathrm{Hg})$ & $156 \pm 20$ & $150 \pm 22$ \\
\hline Diastolic blood pressure (mm Hg) & $85 \pm 10$ & $85 \pm 10$ \\
\hline Total cholesterol (mmol/L) (mg/dil) & $5.3 \pm 1.0(205 \pm 39)$ & $5.2 \pm 1(201 \pm 39)$ \\
\hline $\begin{array}{l}\text { High-density lipoprotein cholesterol } \\
\qquad(\mathrm{mmol} / \mathrm{L})(\mathrm{mg} / \mathrm{dl})\end{array}$ & $1.3 \pm 0.3(50 \pm 12)$ & $1.3 \pm 0.3(50 \pm 12)$ \\
\hline $\begin{array}{l}\text { Low-density lipoprotein cholesterol } \\
\qquad(\mathrm{mmol} / \mathrm{L})(\mathrm{mg} / \mathrm{dl})\end{array}$ & $3.0 \pm 1.0(116 \pm 39)$ & $2.9 \pm 0.9(112 \pm 35)$ \\
\hline Triglyceride (mmol/L) (mg/dl) & $1.5 \pm 0.9(58 \pm 35)$ & $1.7 \pm 1.0(66 \pm 39)$ \\
\hline Lipid-reducing medication & $80 \%$ & $82 \%$ \\
\hline Current smoking & $11 \%$ & $22 \%$ \\
\hline Hypertension medicine use & $63 \%$ & $63 \%$ \\
\hline Diabetes mellitus & $34 \%$ & $26 \%$ \\
\hline Healed myocardial infarction & $15 \%$ & $20 \%$ \\
\hline Coronary bypass & $19 \%$ & $18 \%$ \\
\hline Coronary angioplasty & $12 \%$ & $17 \%$ \\
\hline Angina pectoris & $79 \%$ & $73 \%$ \\
\hline
\end{tabular}

If there was disagreement, the $2 \mathrm{ob}-$ servers reviewed the mammograms together to reach consensus.

BAC was characterized by 2 parallel lines or rings of calcification on mammograms of the right, the left, or both breasts (Figure 1). The intensity of BAC was graded as follows: grade $1=$ mild $\mathrm{BAC}$ (the artery was faintly outlined by calcium; Figure 1); grade $2=$ moderate $\mathrm{BAC}$ (the artery was distinctly outlined by calcium; Figure 1); and grade $3=$ severe BAC (the artery was distinctly outlined by thick columns of calcium; Figure 1).

The baseline data on cardiovascular risk factors were recorded at randomization before study entry. Body mass index was calculated as the ratio of body weight to height (kilograms per square meters). Blood pressure was measured twice with the subject in the sitting position after 5 minutes of rest. Fasting venous blood samples were collected locally and analyzed centrally. Diabetes mellitus was defined as a fasting se-

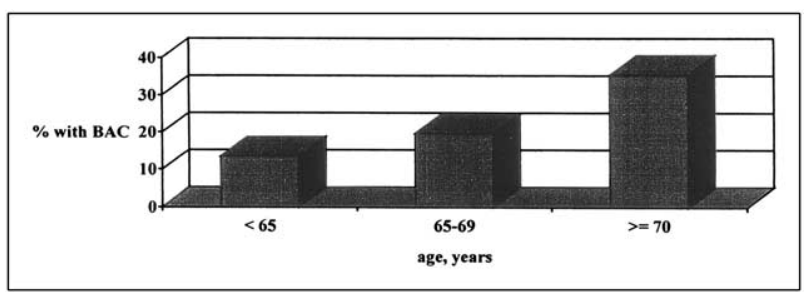

FIGURE 2. Percentage of women with BAC $(n=138)$ per age group.

( $<3$ months); recent percutaneous coronary intervention ( $<6$ months); New York Heart Association class III or IV heart failure; a need for estrogen replacement therapy; or a history of breast cancer, endometrial carcinoma, or deep venous thrombosis or pulmonary embolism. An inclusion criterion for women without established coronary heart disease was the presence of multiple factors (minimum score 4) shown in epidemiologic studies to increase the risk for previous myocardial infarction and coronary death, such as smoking, hypertension, hyperlipidemia, and diabetes mellitus (Table 1).

Standard mammograms (craniocaudal and lateral views) were made for all women included in the RUTH trial at baseline, $\leq 1$ year after randomization, before study entry. The mammograms were stored at the radiology departments of the participating hospitals. The baseline mammograms of 600 of the 610 women included in the Dutch arm of the study were retrieved by the Department of Radiology at the University Medical Center Utrecht, and BAC was scored by 2 independent observers blinded to the clinical data of the patients, using the criteria of Kemmeren et al. ${ }^{3}$ rum glucose level of $>7.8 \mathrm{mmol} / \mathrm{L}(140 \mathrm{mg} / \mathrm{dl})$ or use of oral hypoglycemic medications or insulin. Hypertension was defined as use of antihypertensive medication or a systolic blood pressure $>160 \mathrm{~mm} \mathrm{Hg}$ or a diastolic blood pressure $>95 \mathrm{~mm} \mathrm{Hg}$ on $\geq 2$ occasions before randomization. Hyperlipidemia was defined as use of lipid-reducing medications or a fasting lowdensity lipoprotein cholesterol level $>4.14 \mathrm{mmol} / \mathrm{L}$ $(>160 \mathrm{mg} / \mathrm{dl})$ or a fasting high-density lipoprotein cholesterol level $<1.16 \mathrm{mmol} / \mathrm{L}(<45 \mathrm{mg} / \mathrm{dl})$, with fasting triglycerides $>2.82 \mathrm{mmol} / \mathrm{L}(>250 \mathrm{mg} / \mathrm{dl})$. Smoking was defined as smoking an average of $\geq 10$ cigarettes a day in the 6 months before randomization. All enrolled patients were $\geq 55$ years and had not had menses for $>1$ year. Parity was described as the total number of pregnancies and number of live births.

BAC was defined as the presence of calcium in either or both breasts. The prevalence of BAC was determined, and 95\% CIs were calculated. Classic cardiovascular risk factors (age, body mass index, blood pressure, hyperglycemia, diabetes, smoking, hyperlipidemia) and reproductive factors (parity and age at menopause) were evaluated for their independent effects on the prevalence of BAC. Univariate differences in patient characteristics at baseline were tested by unpaired Student's $t$ tests and chi-square analyses. Logistic regression was used to estimate the independent effect of potential determinants of the presence of BAC and expressed as ORs with $95 \%$ CIs as an approximation of relative risk.

The baseline characteristics of women with and without BAC are listed in Table 2. BAC was detected in 138 of 600 women $(23 \%, 95 \%$ CI 0.20 to 0.26$)$. The calcifications were graded as mild in 100 women 
TABLE 3 Multivariate Relation Between Cardiovascular Risk Factors and BAC

\begin{tabular}{|lcc|}
\hline \multicolumn{1}{|c}{ Variable } & OR & $95 \% \mathrm{Cl}$ \\
\hline Age & 1.11 & $1.07-1.15$ \\
Diabetes & 1.58 & $1.01-2.49$ \\
Parity & & \\
$2-3$ children & 1.84 & $0.81-4.18$ \\
$4-5$ children & 3.81 & $1.62-8.96$ \\
$\geq 6$ children & 6.09 & $2.26-16.39$ \\
\hline
\end{tabular}

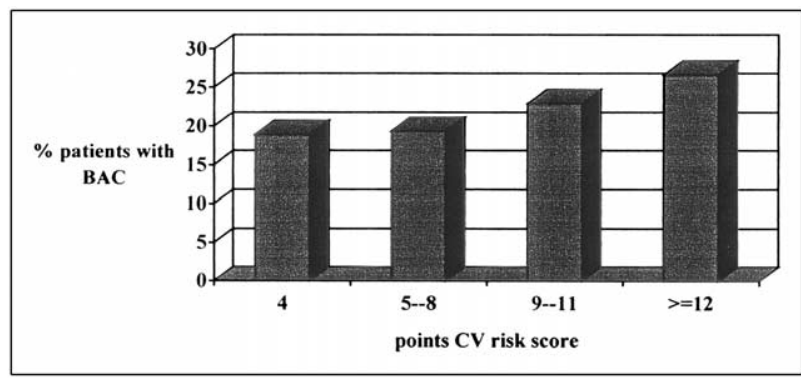

FIGURE 3. Prevalence (percentage) of BAC $(n=138)$ related to cardiovascular $(\mathrm{CV})$ risk score $(\mathrm{n}=600)$.

(72.5\%), moderate in 28 women $(20.3 \%)$, and severe in 10 women $(7.2 \%)$. The prevalence of BAC per age group is shown in Figure 2. The prevalence of BAC $(35.4 \%$; 80 of 226 women) was greatest in women $\geq 70$ years of age (OR 2.9, 95\% CI 2.0 to 4.3). In 17 of 138 women (12\%), BAC was seen in 1 breast only; in all other women, the calcification was symmetrical. Previous coronary heart disease events or angina pectoris with documented coronary artery disease was not independently associated with BAC. Age at menopause was not related to the presence of BAC, whereas parity and BAC were strongly associated. Within the different parity categories (Table 2), the prevalence of BAC increased by $14 \%$ in women with 0 or 1 child, $19 \%$ in women with 2 or 3 children, $35 \%$ in women with 4 or 5 children, and $51 \%$ in women with $\geq 6$ children $(p<0.001)$.

The prevalence of BAC increased significantly ( $\mathrm{p}$ $=0.03$ continuously) with increasing cardiovascular risk score (Figure 3), but multivariate analysis showed only age, diabetes, and parity to be separate independent predictors of BAC (Table 3). With each year of increasing age, the risk for $\mathrm{BAC}$ increased by $11 \%$ (OR 1.11, 95\% CI 1.07 to 1.15). The risk for BAC was $58 \%$ greater in diabetics than in nondiabetics (OR $1.58,95 \%$ CI 1.01 to 2.49 ).

Multivariate analysis adjusted for age, body mass index, and diabetes did not change the magnitude of the association between the prevalence of $\mathrm{BAC}$ and parity. The odds ratio for BAC was 1.8 (95\% CI 0.8 to 4.2) in women with 3 or 4 children, 3.8 (95\% CI 1.6 to 9.0 ) in women with 4 or 5 children, and $6.1(95 \%$ CI 2.3 to 16.4 ) in women with $\geq 6$ children compared with that of women with 0 or 1 child, respectively ( $p$ value for trend 0.000).
In this cross-sectional study of postmenopausal women at risk for coronary heart disease, we found a large prevalence of BAC $(23 \%, 95 \%$ CI 0.20 to 0.26$)$ in mammograms recorded at baseline. The prevalence of BAC was greatest in women aged $\geq 70$ years (35.4\%, OR 2.9, 95\% CI 2.0 to 4.3). Although BAC was significantly more common in women with greater cardiovascular risk scores $(p=0.03)$ and in women with diabetes mellitus $(\mathrm{p}=0.01)$, no specific cardiovascular risk factors besides age and diabetes could be identified to explain the calcium. The significant positive trend between the magnitude of the cardiovascular risk score (Figure 3) and the presence or absence of BAC supports the hypothesis that cardiovascular risk factors are related to these calcium deposits and that BAC may be a marker of atherosclerotic disease. The lack of a correlation between $\mathrm{BAC}$ and traditional cardiovascular risk factors in this cohort is possibly due to the large prevalence of risk factors and the relatively old age of the patients. An interesting finding in our study was the strong and independent association between BAC and parity (Table 2), confirming the results of an earlier study. ${ }^{5}$ This association may be due to hormonal changes in breast tissue and its vascularization during pregnancy and the regression of breast tissue thereafter. In our study population, we had no information on breast-feeding.

Calcium deposits in breast arteries are located in the media of the vessel wall, rather than in the intima, as with calcium in the aorta and the coronary arteries. ${ }^{8}$ It is described as an noninflammatory, age-related phenomenon and differs from atherosclerotic lesions of the intima primarily in the sizes and types of the arteries involved., ${ }^{3,8,9}$ In some reports, it has been exclusively associated with older age and severe diabetes mellitus,,$^{1,2}$ but others also found a greater prevalence of hypertension, family history, and documented coronary artery disease. ${ }^{10}$ A smaller prevalence of BAC has been reported in women using hormone replacement therapy. ${ }^{11,12}$ Because we found the strongest relation with parity, the biologic pathway of these calcium deposits is unclear and possibly related to gestational hormones during pregnancy.

Acknowledgment: We are grateful for the support of A. Hamersma, general manager of the Research Department of Radiology at the University Medical Center Utrecht.

1. Baum JK, Comstock CHJ, Joseph L. Intramammary arterial calcifications associated with diabetes. Radiology 1980;136:61-62.

2. Moshyedi AC, Puthawala AH, Kurland RJ, O'Leary DH. Breast arterial calcification: association with coronary artery disease. Radiology 1995;194:181-183.

3. Kemmeren JM, Beijerinck D, van Noord PA, Banga JD, Deurenberg JJ, Pameijer FA, van der Graaf Y. Breast arterial calcifications: association with diabetes mellitus and cardiovascular mortality. Radiology 1996;201:75-78.

4. Kemmeren JM, van Noord PA, Beijerinck D, Fracheboud J, Banga JD, van der Graaf Y. Arterial calcification found on breast cancer screening mammograms and cardiovascular mortality in women: the DOM project. Am J Epidemiol 1998; 147:333-341.

5. Van Noord PA, Beijerinck D, Kemmeren JM, van der Graaf Y. Mammograms may convey more than breast cancer risk: breast arterial calcification and arterio-sclerotic related diseases in women of the DOM cohort. Eur J Cancer Prev 1996;5:483-487. 
6. Mosca L, Barrett-Connor E, Wenger NK, Collins P, Grady D, Kornitzer M, Moscarelli E, Paul S, Wright TJ, Helterbrand JD, et al. Design and methods of the Raloxifene Use for the Heart (RUTH) study. Am J Cardiol 2001;88:392-395. 7. Wenger NK, Barrett-Connor E, Collins P, Grady D, Kornitzer M, Mosca L, Sashegyi A, Baygani SK, Anderson PW, Moscarelli E. Baseline characteristics of participants in the Raloxifene Use for the Heart (RUTH) Trial. Am J Cardiol 2002;90:1204-1210.

8. Nielsen BB, Holm NV. Calcification in breast arteries. Acta Path Microbiol Immunol Scand 1985;93:13-16.

9. Sickles EA, Galvin HB. Breast arterial calcification in association with dia- betes mellitus: too weak a correlation to have clinical utility. Radiology 1985 ; 155:577-579.

10. Crystal P, Crystal E, Leor J, Friger M, Katzinovitch G, Strano S. Breast artery calcium on routine mammography as a potential marker for increased risk of cardiovascular disease. Am J Cardiol 2000;86:216-217.

11. Leinster SJ, Whitehouse GH. Factors which influence the occurrence of vascular calcification of the breast. Br J Radiol 1987;60:457-458.

12. Cox J, Simpson W, Walshaw D. An interesting byproduct of screening: assessing the effect of HRT on arterial calcification in the female breast. $J$ Med Screen 2002;9:38-39.

\title{
Comparative Effects of Carvedilol and Amiodarone on Conversion and Recurrence Rates of Persistent Atrial Fibrillation
}

\author{
Emmanuel M. Kanoupakis, MD, Emmanuel G. Manios, MD, Hercules E. Mavrakis, MD, \\ Panos G. Tzerakis, MD, Helen K. Mouloudi, MD, and Panos E. Vardas, MD, PhD
}

\begin{abstract}
Pretreatment with antiarrhythmic agents could improve cardioversion and recurrence rates in patients with persistent atrial fibrillation. In a prospective controlled trial, 145 patients were randomly assigned to treatment with carvedilol, amiodarone, or placebo for 4 weeks before electrical cardioversion. Although the $\mathbf{2}$ drugs had similar effects on cardioversion rates, amiodarone was superior in terms of sinus rhythm maintenance after conversion. (c)2004 by Excerpta Medica, Inc.
\end{abstract}

(Am J Cardiol 2004;94:659-662)

$\mathbf{T}$ o prevent atrial electrical remodeling in patients with atrial fibrillation (AF), amiodarone is administered before electrical cardioversion to facilitate the termination of the arrhythmia and the subsequent maintenance of normal sinus rhythm. ${ }^{1-3}$ However, a wide range of side effects limits the clinical value of amiodarone $^{4}$ and has resulted in a shift in research activities toward other compounds. Although $\beta$ blocker therapy has been used to control ventricular rate in persistent or permanent AF, only a few studies have examined the effectiveness of $\beta$ antagonists for the maintenance of sinus rhythm after cardioversion. ${ }^{5-8}$ In this prospective trial, we examined the conversion and recurrence rates of patients with persistent AF randomly assigned to treatment with carvedilol, amiodarone, or placebo. We also investigated the possible effects of these drugs on the electrical properties of the remodeled atrium.

The study included patients with persistent $\mathrm{AF}$ lasting $>7$ days who were $<80$ years old, had ventricular rates at rest of $>60$ beats/min, systolic blood pressure $>90 \mathrm{~mm} \mathrm{Hg}$, and left atrial diameter $<50$

\footnotetext{
From the Department of Cardiology, Heraklion University Hospital, Heraklion, Greece. Dr. Vardas's address is: Cardiology Department, Heraklion University Hospital, PO Box 1352 Stavrakia, Heraklion, Crete, Greece. E-mail: cardio@med.voc.gr. Manuscript received February 6, 2004; revised manuscript received and accepted May 14 , 2004.
}

mm. Patients who had left ventricular ejection fractions of $<40 \%$, concomitant treatment with class I or III antiarrhythmic drugs, recorded amiodarone use during the preceding 6 months, and contraindications for $\beta$ blockade, such as conduction disturbances, asthma, or severe chronic obstructive pulmonary disease, were excluded.

Thyroid dysfunction and abnormal electrolyte concentrations were ruled out in all subjects. Signed written consent was obtained from all subjects before their participation in the study, which was approved by the ethics committee of our institution.

On entry into the study (4 weeks before internal cardioversion), 145 eligible patients were randomly assigned to 3 treatment groups (A, B, or $\mathrm{C}$ ) by a computer-generated model. Patients assigned to group A were to receive carvedilol at a starting dose of 6.25 $\mathrm{mg}$ twice daily, which was titrated up to $25 \mathrm{mg}$ twice daily depending on patients' tolerance. Group B included patients who received amiodarone $600 \mathrm{mg}$ /day for the first 2 weeks (after entry into the study), which was reduced to a subsequent dose of $200 \mathrm{mg} /$ day up to the end of the study. No antiarrhythmic drugs were administered to patients in group $\mathrm{C}$, who served as controls. In those patients in whom it was necessary to control ventricular response in the period before conversion, digitalis was administered.

All patients were properly anticoagulated by oral treatment with acenocoumarol, which resulted in an international normalized ratio of 2.5 to 3.5 for $\geq 4$ weeks before electrical cardioversion.

In those patients who did not spontaneously convert to sinus rhythm, internal cardioversion was performed in the electrophysiology laboratory with a specially designed balloon-guided catheter for energy delivery (ALERT, EPMedSystems, Inc., West Berlin, New Jersey). An intracardiac electrical shock (ranging from $3 \mathrm{~J}$ to a maximum of $15 \mathrm{~J}$, increased in steps of $3 \mathrm{~J}$ when necessary) was used for atrial defibrillation (ALERT Companion, EPMed Systems, Inc.).

In all patients, a standard quadripolar catheter (USCI, Inc., Norcross, Georgia) was advanced to the 